\title{
Spatial Patterns of Viable Spore Deposition of Gibberella zeae in Wheat Fields
}

\author{
David G. Schmale III, Denis A. Shah, and Gary C. Bergstrom
}

First and third authors: Department of Plant Pathology, Cornell University, Ithaca, NY 14853; and second author: Department of Plant Pathology, NYSAES, Geneva, NY 14456.

Accepted for publication 6 January 2005.

\begin{abstract}
Schmale, D. G., III, Shah, D. A., and Bergstrom, G. C. 2005. Spatial patterns of viable spore deposition of Gibberella zeae in wheat fields. Phytopathology 95:472-479.

An increased understanding of the epidemiology of Gibberella zeae will contribute to a rational and informed approach to the management of Fusarium head blight (FHB). An integral phase of the FHB cycle is the deposition of airborne spores, yet there is no information available on the spatial pattern of spore deposition of G. zeae above wheat canopies. We examined spatial patterns of viable spore deposition of G. zeae over rotational (lacking cereal debris) wheat fields in New York in 2002 and 2004. Viable, airborne spores (ascospores and macroconidia) of G. zeae were collected above wheat spikes on petri plates containing a selective medium and the resulting colonies were counted. Spores of G. zeae were collected over a total of 68 field environments (three wheat fields during

were visualized by contour plots of spore counts over entire fields. The spatial pattern of spore deposition was unique for each field environment during each day and night sample period. Spore deposition patterns during individual sample periods were classified by spatial analysis by distance indices (SADIE) statistics and Mantel tests. Both analyses indicated that the majority (93\%) of the spore deposition events were random, with the remainder being aggregated. All of the aggregated patterns were observed during the night. Observed patterns of spore deposition were independent of the mean number of viable spores deposited during individual sample periods. The spatial pattern for cumulative spore deposition during anthesis in both years became aggregated over time. Contour maps of daily and cumulative spore deposition could be compared with contour maps of FHB incidence to gain insights into inoculum thresholds and the timing of effective inoculum for infection.
\end{abstract} 54 day and night sample periods over 2 years) from spike emergence to kernel milk stages of local wheat. Spatial patterns of spore deposition

There has been increasing recognition and interest in the spatial component of plant disease epidemics $(4,8,10,11,24,50)$. The analysis of spatial patterns may suggest the process or processes responsible for observed patterns, revealing the influence of factors such as wind (21) and rain (39) on the distribution of plant pathogens. Spatial patterns may be used to infer sources of inoculum for local epidemics $(11,24)$, and the analysis of these patterns may aid in the development of risk models for managing plant disease $(7,10)$.

Gibberella zeae (Schwein.) Petch (anamorph Fusarium graminearum Schwabe) causes Fusarium head blight (FHB) of wheat and barley (1). Grain infected with $G$. zeae potentially is contaminated with mycotoxins which are detrimental to human and livestock health $(30,33,40)$. G. zeae overwinters in the residues of corn and small grains (46). In the spring and summer months, perithecia develop from these residues and forcibly discharge ascospores into the air $(1,41,49)$. Several investigators have trapped airborne spores (ascospores and macroconidia) of G. zeae within and above small grain canopies (12,14,19, $20,25,26,28,32,42-45)$. These studies have shown that spores of G. zeae are common in the air during spring and summer months during both day and night under a broad range of environmental conditions. The airborne ascospores (rather than macroconidia) generally are considered to be the primary inoculum for infection of wheat spikes $(1,41,49)$.

Corresponding author: D. G. Schmale III; E-mail address: dgs25@cornell.edu

DOI: 10.1094/PHYTO-95-0472

(c) 2005 The American Phytopathological Society
Additional keyword: Fusarium graminearum.

Little is known about the spatial pattern of $G$. zeae in the air over wheat fields. One or a few volumetric spore samplers traditionally have been used to measure the number or density of G. zeae spores present in agricultural fields $(12,14,25,28,29,32)$. However, the use of these spore samplers at one or a few locations in a field is insufficient to address questions of spatial pattern. If spores of G. zeae are not distributed at random over wheat fields, the use of one or a few spore samplers in a field may not provide an appropriate measure of inoculum levels of G. zeae.

Recently, we developed a quick, inexpensive sampling technique for observing viable spore deposition of $G$. zeae at numerous locations over large areas of wheat (43-45) and corn (42) fields. Petri plates containing Fusarium-selective medium (FSM) were placed in crop canopies during the day and night and viable spores of G. zeae were collected (43-45). Analyses of variance for spore counts among sample locations in the wheat fields indicated variation in spore deposition for many of the sample periods $(43,44)$. These tests suggested nonrandom (aggregated) patterns of spore deposition. As a preliminary analysis of spatial pattern, we calculated variance-to-mean (VM) ratios for spore deposition in each of the wheat field environments during each day and night sample period (7). The VM ratios indicated that there were potentially aggregated patterns of spore deposition. Based on these analyses, we hypothesized that spores of G. zeae are not deposited randomly above wheat canopies during individual day and night periods spanning spike emergence and kernel milk growth stages of local wheat. However, VM ratios provide only a simple index of spatial pattern (24), and patterns based on VM ratios often are dependent on sample size, with different patterns potentially giving the same index (38). As a result of these limitations, we chose three additional approaches to spatial analysis to test our hypothesis of nonrandom spore deposition; contour maps 
(37), spatial analysis by distance indices (SADIE) (34), and Mantel tests (27). These methods incorporated the spatial locations of the sample units into the analyses, thus providing a better indication of spatial pattern $(9,35)$.

The objective of this study was to determine the spatial patterns of spore deposition of $G$. zeae during the day and night in rotational wheat fields lacking corn or other cereal debris, known sources of airborne inoculum of $G$. zeae. Preliminary results of this study have been published (43).

\section{MATERIALS AND METHODS}

The experiments were done at the Robert B. Musgrave research farm in Aurora, NY, in May and June 2002 and June 2004. In 2002, experiments were conducted in a single wheat field (field A). In 2004, experiments were conducted in two wheat fields (fields C and D). The wheat crop in both years was sown in September of the preceding year (43) following harvest of soybean and plowing of residues. All of the experimental fields lacked residues of corn or small grains (a potential inoculum source of G. zeae), although some large fields within the vicinity of the farm contained overwintered residues. Documented inoculum deposition gradients for G. zeae have been associated with small, concentrated local sources $(12,15)$. However, large area sources of G. zeae are unlikely to produce deposition gradients in local fields $(16,48)$. Rainfall was recorded every hour at a weather station in Scipioville, NY (approximately $4 \mathrm{~km}$ from the farm). Hourly wind data was not available.

Sampling. Petri plates $(90 \mathrm{~mm}$ in diameter; surface area $=$ $283 \mathrm{~mm}^{2}$ ) containing FSM were used to collect viable spores of G. zeae above wheat canopies (43-45). The FSM consisted of a modified Nash-Snyder formulation, prepared as described by Burgess et al. (6) with an increased level of Neomycin sulfate at $0.175 \mathrm{~g} /$ liter. Plates were placed $30 \mathrm{~cm}$ above wheat spikes on wooden T-shaped stakes. In all, 24 stakes were placed in field A and 12 stakes were placed in each of fields C and D. Two petri plates were placed on each stake. Sample locations were equidistant from each other in each field. In field A, a stake was positioned every $30.5 \mathrm{~m}$, covering a rectangle 91.4 by $152.4 \mathrm{~m}$ wide. In fields $C$ and $D$, a stake was positioned every $15.2 \mathrm{~m}$, covering a rectangle 45.7 by $30.5 \mathrm{~m}$ wide.

Spatial patterns of spore deposition were analyzed for 68 fieldsample period combinations, each referred to as a field environment. Consecutive sample periods covered the interval from Zadoks growth stage (GS) 50 (spike emergence) to GS 75 (kernel milk) in 2002, and Zadoks GS 60 (beginning of anthesis) to GS 71 (kernel watery ripe) in 2004. For field A, collection started at sunrise on 27 May and ended at sunrise on 15 June. For fields C and $\mathrm{D}$, collection started at sunrise on 2 June and ended at sunrise on 8 June. Plates were collected from sunrise to sunset (approximately 6:00 a.m. to 8:00 p.m.), and from sunset to sunrise (approximately 8:00 p.m. to 6:00 a.m.) in both years. Plates were covered immediately following exposure and incubated for 5 to 7 days at room temperature in the laboratory, so that the colonies were large enough to be identified but had not yet grown together. The total number of resulting $F$. graminearum colonies was counted and recorded (43-45). Colonies of several Fusarium spp. were recovered, but only salmon-colored colonies typical of $F$. graminearum were counted and recorded. A subset of the colonies putatively identified as $F$. graminearum was transferred to carrot agar for verification of the $G$. zeae perfect state $(5,6)$.

Estimation of missing data. Data could not be collected from 57 of the 2,252 plates exposed over all three fields because of damage by birds. There were seven sample periods for which data from both plates were missing (five for field A and two for field D). For the remaining missing plate counts, there was at least one plate count available in each case. A data imputation (substitution) method was used to estimate missing data from available data prior to analysis. Using data from field A, we found that the counts of both replicate plates were closely correlated $\left(R^{2}=\right.$ 0.946; $P<0.001 ; n=857)$. If $p_{1}$ and $p_{2}$ are the counts on replicate plates 1 and 2 , then $\ln \left(p_{1}+1\right)=0.956 \ln \left(p_{2}+1\right)$. The natural
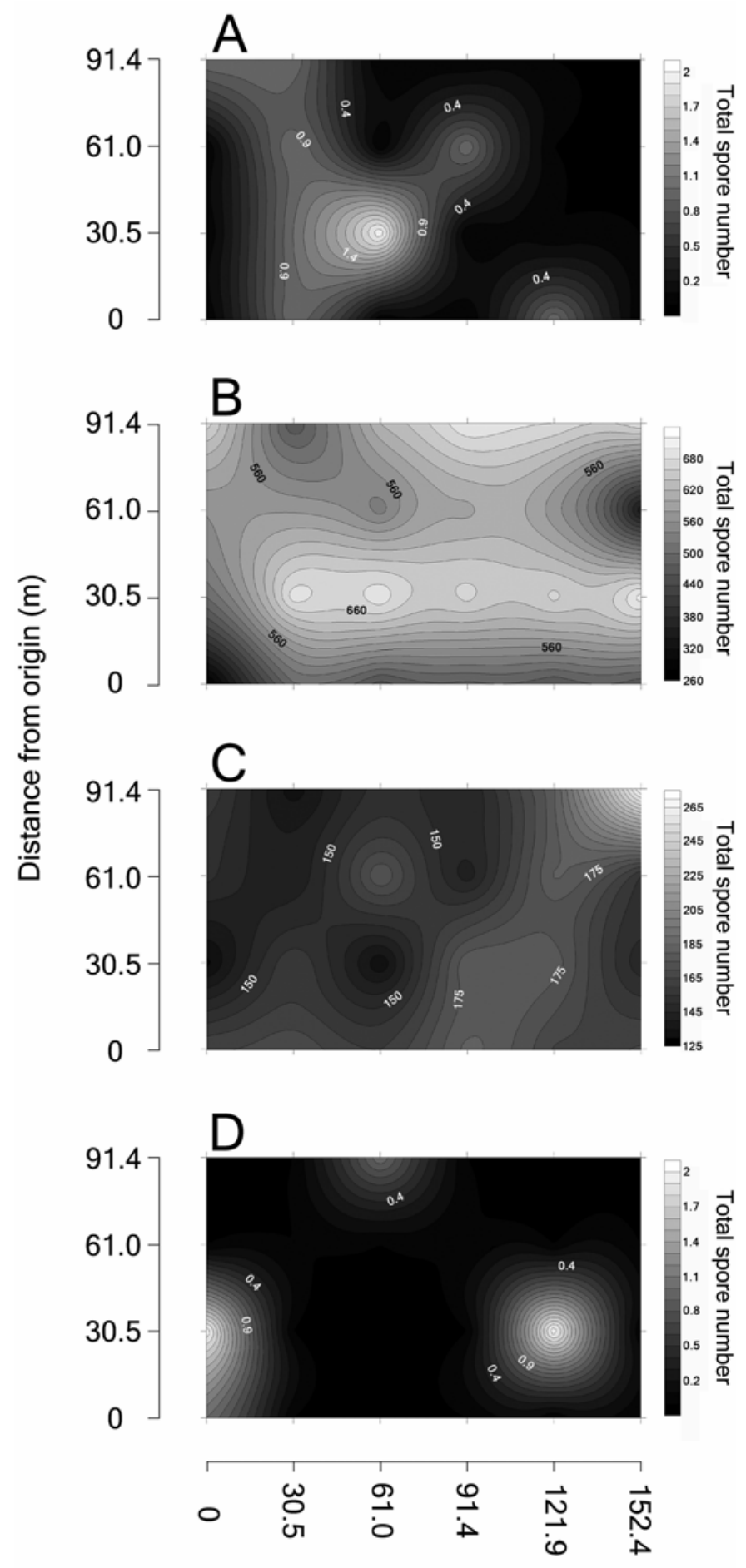

Distance from origin $(\mathrm{m})$

Fig. 1. Example contour maps depicting the spatial pattern of viable spore deposition of Gibberella zeae above the wheat canopy in field A in 2002 for sample periods A, 15 (day), B, 20 (night), C, 22 (night), and D, 27 (day). Contours were constructed based on data collected at 24 equidistant sample locations within the field. Total spore counts (from both plates combined) at each sample location were matched with their associated $\left(X_{i}, Y_{i}\right)$ positions, and contour maps were constructed from these coordinates. Legends for the total number of spores deposited are presented to the immediate right of the contour maps. 

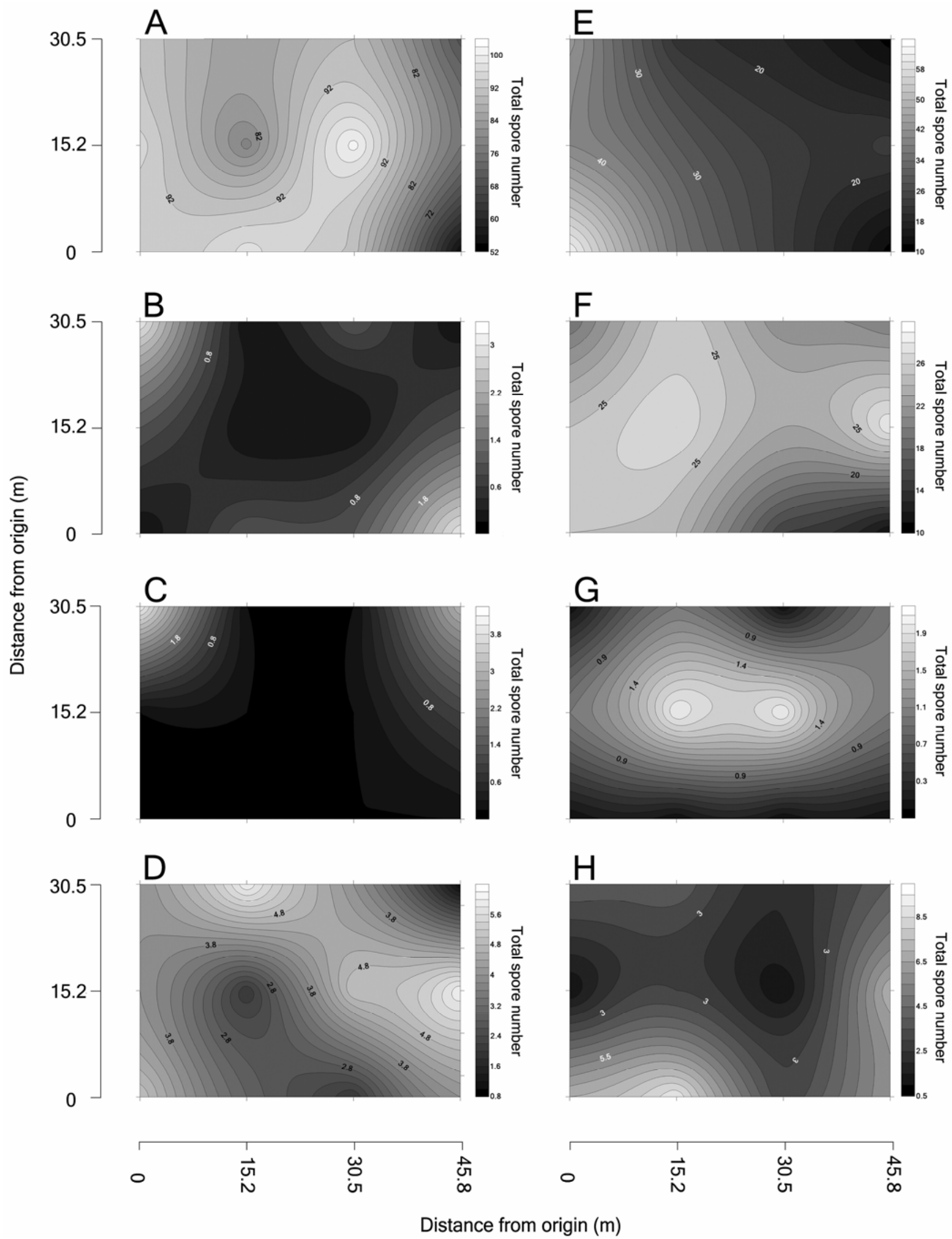

Fig. 2. Example contour maps depicting the spatial pattern of viable spore deposition of Gibberella zeae above the wheat canopies in fields C and D in 2004. For field C, sample periods A, 42 (night), B, 45 (day), C, 47 (day), and D, 51 (night) are presented. For field D, sample periods E, 44 (night), F, 41 (day), G, 51 (day), and $\mathbf{H}, 52$ (night) are presented. Contours were constructed based on data collected at 12 equidistant sample locations within the fields. Total spore counts (from both plates combined) at each sample location were matched with their associated $\left(X_{i}, Y_{i}\right)$ positions, and contour maps were constructed from these coordinates. Legends for the total number of spores deposited are presented to the immediate right of the contour maps. 


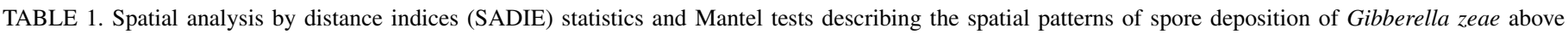
wheat canopies during individual sample periods in 2002 and 2004

\begin{tabular}{|c|c|c|c|c|c|c|c|c|c|c|c|}
\hline \multirow[b]{2}{*}{ Period } & \multirow[b]{2}{*}{ Field } & \multirow[b]{2}{*}{ Day or night ${ }^{\mathrm{a}}$} & \multirow[b]{2}{*}{$N^{\mathrm{b}}$} & \multirow[b]{2}{*}{ Mean $^{c}$} & \multirow[b]{2}{*}{ Rain (mm) } & \multicolumn{3}{|c|}{ SADIE statistics } & \multicolumn{3}{|c|}{ Mantel statistics } \\
\hline & & & & & & $I_{a}^{\mathrm{d}}$ & $P_{a}^{\mathrm{e}}$ & Pattern $^{\mathrm{f}}$ & $r^{\mathrm{g}}$ & $P^{\mathrm{h}}$ & Pattern $^{\mathrm{i}}$ \\
\hline 1 & A & Day & $24 *$ & $<1$ & $\ldots$ & 0.817 & 0.854 & Random & 0.037 & 0.704 & Random \\
\hline 2 & A & Night & 24 & 4 & $\ldots$ & 1.119 & 0.209 & Random & 0.104 & 0.186 & Random \\
\hline 3 & A & Day & $24 *$ & 2 & $\ldots$ & 1.209 & 0.132 & Random & 0.177 & 0.087 & Random \\
\hline 4 & A & Night & 24 & 7 & $\ldots$ & 0.811 & 0.909 & Random & -0.008 & 0.984 & Random \\
\hline 5 & A & Day & $24 *$ & 7 & $\ldots$ & 1.419 & 0.031 & Random & 0.194 & 0.033 & Random \\
\hline 6 & A & Night & 24 & 12 & 0.33 & 1.047 & 0.315 & Random & 0.072 & 0.374 & Random \\
\hline 7 & A & Day & $24 *$ & $<1$ & $\ldots$ & 1.091 & 0.265 & Random & 0.107 & 0.325 & Random \\
\hline 8 & A & Night & 24 & 41 & $\ldots$ & 0.956 & 0.527 & Random & 0.056 & 0.515 & Random \\
\hline 9 & A & Day & $24 *$ & 2 & 0.26 & 1.129 & 0.198 & Random & 0.003 & 0.921 & Random \\
\hline 10 & A & Night & $24 *$ & 37 & $\ldots$ & 1.154 & 0.163 & Random & 0.009 & 0.825 & Random \\
\hline 11 & A & Day & $24 *$ & $<1$ & $\ldots$ & 0.932 & 0.589 & Random & -0.139 & 0.155 & Random \\
\hline 12 & A & Night & 24 & 16 & 0.02 & 1.097 & 0.278 & Random & 0.074 & 0.543 & Random \\
\hline 13 & A & Day & $24 *$ & $<1$ & $\ldots$ & 1.316 & 0.056 & Random & 0.105 & 0.276 & Random \\
\hline 14 & A & Night & 24 & 9 & $\ldots$ & 0.846 & 0.804 & Random & -0.108 & 0.141 & Random \\
\hline 15 & A & Day & 24 & $<1$ & $\ldots$ & 1.160 & 0.152 & Random & -0.056 & 0.555 & Random \\
\hline 16 & A & Night & $24 *$ & 2 & $\ldots$ & 0.855 & 0.800 & Random & 0.015 & 0.822 & Random \\
\hline 18 & A & Night & $24 *$ & 37 & 0.02 & 0.973 & 0.476 & Random & -0.079 & 0.369 & Random \\
\hline 20 & A & Night & 24 & 564 & 0.22 & 1.092 & 0.252 & Random & 0.151 & 0.066 & Random \\
\hline 21 & A & Day & $24 *$ & 15 & 0.05 & 1.121 & 0.216 & Random & 0.008 & 0.892 & Random \\
\hline 22 & A & Night & 24 & 163 & $\ldots$ & 1.442 & 0.027 & Random & 0.147 & 0.166 & Random \\
\hline 24 & A & Night & 24 & 106 & $\ldots$ & 2.004 & $<0.001$ & Aggregated & 0.351 & $<0.001$ & Aggregated \\
\hline 25 & A & Day & 24 & $<1$ & $\ldots$ & 0.855 & 0.783 & Random & -0.021 & 0.937 & Random \\
\hline 26 & A & Night & 24 & 9 & $\ldots$ & 1.413 & 0.040 & Random & 0.123 & 0.179 & Random \\
\hline 27 & A & Day & 24 & $<1$ & $\ldots$ & 0.911 & 0.656 & Random & 0.024 & 0.792 & Random \\
\hline 28 & A & Night & $24 *$ & 35 & $\ldots$ & 2.067 & $<0.001$ & Aggregated & 0.419 & $<0.001$ & Aggregated \\
\hline 29 & A & Day & 24 & $<1$ & $\ldots$ & 1.211 & 0.125 & Random & -0.011 & 0.933 & Random \\
\hline 30 & A & Night & $24 *$ & 6 & $\ldots$ & 1.496 & 0.016 & Random & 0.149 & 0.169 & Random \\
\hline 31 & A & Day & 24 & $<1$ & $\ldots$ & 0.773 & 0.961 & Random & -0.103 & 0.321 & Random \\
\hline 32 & A & Night & 24 & 3 & $\ldots$ & 0.757 & 0.973 & Random & -0.052 & 0.543 & Random \\
\hline 34 & A & Night & $24 *$ & 117 & $\ldots$ & 1.037 & 0.355 & Random & 0.125 & 0.215 & Random \\
\hline 36 & A & Night & $24 *$ & 47 & 0.45 & 1.011 & 0.402 & Random & 0.124 & 0.260 & Random \\
\hline 38 & A & Night & $24 *$ & 172 & 0.28 & 1.167 & 0.153 & Random & 0.046 & 0.488 & Random \\
\hline 41 & $\mathrm{C}$ & Day & 12 & 24 & 0.01 & 1.322 & 0.050 & Random & 0.096 & 0.445 & Random \\
\hline 42 & $\mathrm{C}$ & Night & 12 & 85 & $\ldots$ & 1.288 & 0.065 & Random & 0.252 & 0.088 & Random \\
\hline 43 & $\mathrm{C}$ & Day & 12 & 2 & $\ldots$ & 1.091 & 0.274 & Random & 0.123 & 0.416 & Random \\
\hline 44 & $\mathrm{C}$ & Night & 12 & 15 & $\ldots$ & 1.105 & 0.242 & Random & 0.112 & 0.463 & Random \\
\hline 45 & $\mathrm{C}$ & Day & 12 & 1 & $\ldots$ & 1.043 & 0.338 & Random & 0.086 & 0.524 & Random \\
\hline 46 & $\mathrm{C}$ & Night & 12 & 7 & $\ldots$ & 1.088 & 0.262 & Random & -0.046 & 0.762 & Random \\
\hline 47 & $\mathrm{C}$ & Day & 12 & 1 & $\ldots$ & 1.029 & 0.363 & Random & 0.241 & 0.143 & Random \\
\hline 48 & $\mathrm{C}$ & Night & 12 & 2 & $\ldots$ & 0.863 & 0.817 & Random & 0.007 & 0.806 & Random \\
\hline 49 & $\mathrm{C}$ & Day & 12 & $<1$ & $\ldots$ & 1.200 & 0.103 & Random & 0.191 & 0.191 & Random \\
\hline 50 & $\mathrm{C}$ & Night & 12 & 4 & $\ldots$ & 0.826 & 0.847 & Random & -0.122 & 0.369 & Random \\
\hline 51 & $\mathrm{C}$ & Day & 12 & 1 & $\ldots$ & 1.254 & 0.076 & Random & 0.184 & 0.212 & Random \\
\hline 52 & $\mathrm{C}$ & Night & 12 & 3 & $\ldots$ & 1.086 & 0.258 & Random & 0.030 & 0.690 & Random \\
\hline 54 & $\mathrm{C}$ & Night & 12 & 1 & $\ldots$ & 1.180 & 0.150 & Random & 0.211 & 0.156 & Random \\
\hline 41 & $\mathrm{D}$ & Day & 12 & 22 & 0.01 & 1.075 & 0.279 & Random & 0.149 & 0.317 & Random \\
\hline 42 & $\mathrm{D}$ & Night & $12 *$ & 170 & $\ldots$ & 1.744 & $<0.001$ & Aggregated & 0.553 & $<0.001$ & Aggregated \\
\hline 43 & $\mathrm{D}$ & Day & 12 & 3 & $\ldots$ & 0.919 & 0.637 & Random & -0.144 & 0.265 & Random \\
\hline 44 & $\mathrm{D}$ & Night & $12 *$ & 29 & $\ldots$ & 1.780 & $<0.001$ & Aggregated & 0.593 & $<0.001$ & Aggregated \\
\hline 45 & $\mathrm{D}$ & Day & 12 & 1 & $\ldots$ & 0.848 & 0.895 & Random & -0.246 & 0.019 & Random \\
\hline 46 & $\mathrm{D}$ & Night & $12 *$ & 6 & $\ldots$ & 1.462 & 0.016 & Random & 0.260 & 0.059 & Random \\
\hline 48 & $\mathrm{D}$ & Night & 12 & 4 & $\ldots$ & 1.184 & 0.170 & Random & 0.057 & 0.813 & Random \\
\hline 49 & $\mathrm{D}$ & Day & 12 & 1 & $\ldots$ & 0.847 & 0.917 & Random & -0.099 & 0.331 & Random \\
\hline 50 & $\mathrm{D}$ & Night & 12 & 8 & $\ldots$ & 1.023 & 0.383 & Random & 0.079 & 0.684 & Random \\
\hline 51 & $\mathrm{D}$ & Day & 12 & 1 & $\ldots$ & 1.143 & 0.183 & Random & 0.059 & 0.492 & Random \\
\hline 52 & $\mathrm{D}$ & Night & 12 & 4 & $\ldots$ & 0.904 & 0.666 & Random & -0.065 & 0.674 & Random \\
\hline 54 & $\mathrm{D}$ & Night & 12 & 3 & $\ldots$ & 1.039 & 0.330 & Random & 0.171 & 0.203 & Random \\
\hline
\end{tabular}

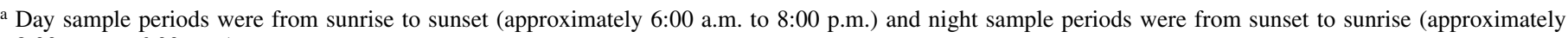
8:00 p.m. to 6:00 a.m.).

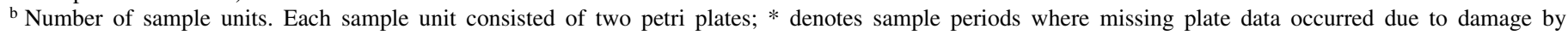
birds.

c Mean number of spores of $G$. zeae collected per sample locations (two plates per location) for the given sample period.

d SADIE index of aggregation $\left(I_{a}\right)(37)$. Uniform, random, and aggregated spatial patterns of counts are suggested by $I_{a}$ of $<1$, $=1$, or $>1$, respectively.

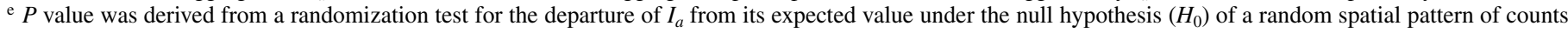
(37).

${ }^{\mathrm{f}}$ Descriptions of random or aggregated spatial patterns of counts. $H_{0}$ was rejected if $P_{a}<0.01$, favoring the alternative hypothesis of aggregation.

g Normalized Mantel statistic $(r)$.

${ }^{\text {h }} P$ value was derived from a randomization test for the departure of $r$ from its expected value under $H_{0}$ of a random spatial pattern of counts.

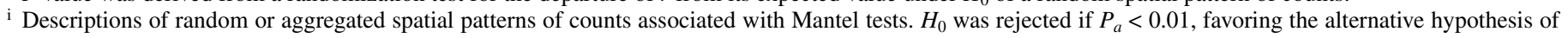
aggregation. 
logarithmic transformation was used to model the counts because the variance in counts increased with the mean. The equation was used to estimate the missing counts, given that data were available for one of the plates at a location.

If data were missing from both plates, then the total count at that location was estimated under the assumption of spatial connectedness among immediately adjacent locations. The neighborhood $n_{i}$ of a location $l_{i}$ was defined as consisting of all immediate sampling locations under the "queen" definition of spatial connectedness (51). The total at $l_{i}$ was then estimated as the mean of the total counts over $n_{i}$.

Contour maps. The spatial pattern of spore counts for each field environment within each sample period was depicted visually by contour maps using Surfer software (version 8; Golden Software Inc., Golden, CO) (37). Sample locations were plotted on a Cartesian plane with an assigned two-dimensional position $\left(X_{i}\right.$, $\left.Y_{i}\right)$. Total spore counts (from both plates combined) at each sample location were matched with their associated $\left(X_{i}, Y_{i}\right)$ positions, and grids based on these positions were created in Surfer. Black and white contour maps were constructed from these grids.

SADIE and Mantel tests. No single measure can adequately describe spatial structure in data, and the use of more than one statistic is advocated (36). The data sets did not contain a large enough number of sample locations to justify the use of certain autocorrelation measures (such as Moran's $I$ and Geary's $c$ ) which have underlying normal distributional assumptions (23). Therefore, we used two nonparametric methods (SADIE statistics and Mantel tests), in which the significance of the test statistic is determined by permutation techniques. Note that, with small numbers of sample locations, it is difficult to detect spatial paterns with most test statistics. The ability of SADIE to detect spatial patterns with small sample sizes has not yet been investigated, and it is generally recommended that $>20$ sample locations be used with Mantel tests (18). These inherent limitations in the statistical tests should be kept in mind when interpreting significance levels that are not conservative.

SADIE was used to analyze spatial associations among spore counts at individual locations in each field environment during each sample period in both years (34). SADIE measures spatial patterns for count data mapped in two dimensions (35). The degree of nonrandomness (aggregation) in a set of count data is measured by comparing the observed spatial pattern with rearrangements of the data where the counts are randomly distributed among the sample units. SADIE calculates an index of aggregation $\left(I_{a}\right)$ based on the distance to regularity $(D)$ of the

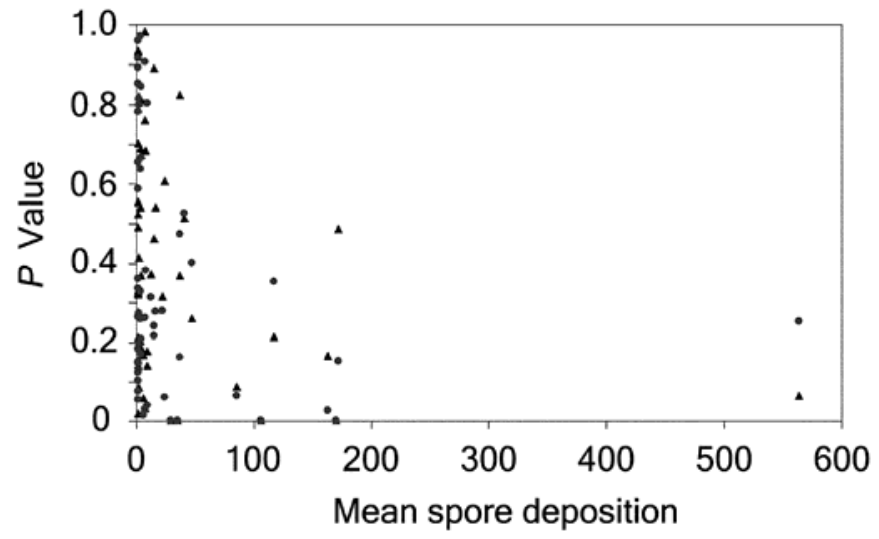

Fig. 3. Scatter plots of mean spore deposition of Gibberella zeae above wheat canopies per sample period and the $P$ values obtained from spatial analysis by distance indices (circles) and Mantel tests (triangles). Mean spore deposition refers to the average number of spores of $G$. zeae collected at a sample location in a field during an individual sample period. We rejected the null hypothesis of a random pattern if $P<0.01$, favoring the alternative hypothesis of aggregation. sample and the mean distance to regularity $\left(E_{a}\right)$ for the randomized rearrangements of the sample (35). $D$ is the minimum distance that individuals (i.e., spores) in the sample would have to move, such that all of the sample units contained the same number of individuals. $E_{a}$ is the average distance to regularity of all of the randomized rearrangements of the sample. $I_{a}$ is defined as $I_{a}=$ $D / E_{a}(35)$. Aggregated arrangements tend to have large distances to regularity, whereas more regular (uniform) arrangements tend to have smaller distances to regularity. Regular, random, and aggregated patterns are suggested when $I_{a}$ is $<1,=1$, or $>1$, respectively (35). SADIE performs a formal test of randomness $\left(P_{a}\right)$ for determining significance, in which the percentages of distances from the randomized rearrangements are used (35). For our tests, we rejected the null hypothesis of a random pattern if $P_{a}<0.01$, favoring the alternative hypothesis of aggregation. Each $P_{a}$ was based on 5,967 permutations of the respective data set. The analysis was done using the 2001 version of SADIE (J. N. Perry, Rothamsted Research, available online from Rothamsted Research) $(34,35)$.

The Mantel test (27) was performed using a SAS program (SAS Institute, Cary, NC) written by Barry Moser, Department of Experimental Statistics, Louisiana State University. The significance of the normalized Mantel statistic ( $r$ ) was determined from 10,000 permutations. For our tests, we rejected the null hypothesis of a random pattern if $P<0.01$, favoring the alternative hypothesis of aggregation.

Spatial patterns and mean spore deposition. We constructed scatter plots to observe the relationship between mean spore deposition (the average number of spores of G. zeae collected at a sample location in a field during an individual sample period) and the $P$ values obtained from SADIE and Mantel tests.

Cumulative spore deposition patterns. The spatial patterns of cumulative spore deposition were analyzed over 14 consecutive day and night sample periods during anthesis in both years (sample periods 17 to 30 in field A and 41 to 54 in fields C and D) (43). Anthesis is a critical period in the susceptibility of wheat to FHB. Contour maps were created for cumulative counts of spores over entire fields for each consecutive sample period in both years.

\section{RESULTS}

Contour maps. The contour maps revealed unique spatial patterns of spore deposition for all field environments within each day and night sample period in both years. Some examples, representing major (averaging 50 or more colonies per plate) and minor spore deposition events during both day and night, are presented in Figures 1 and 2. These maps are a visual representation of the spatial pattern of spore counts for a field environment during an individual sample period. Spore deposition counts frequently differed among sample locations during individual sample periods, and counts at individual sample locations varied over time.

SADIE and Mantel tests. SADIE statistics and Mantel tests indicated that the majority $(93 \%)$ of the spore deposition events was random, with the remainder being aggregated (Table 1). Of the random patterns of spore deposition, 24 occurred during the day and 29 during the night. All four of the aggregated patterns occurred during the night. Only random patterns of spore deposition were evident during sample periods with rainfall (Table 1).

Spatial patterns and mean spore deposition. Spatial patterns of spore deposition were not dependent on the size of the spore load during an individual sample period. Both SADIE and Mantel tests showed that aggregated and random patterns of spore deposition were observed during minor and major spore deposition events (Fig. 3).

Cumulative spore deposition patterns. Cumulative counts of spores over 14 consecutive day and night sample periods during peak anthesis in fields A, C, and D are presented in Table 2. For 
field A, the spatial pattern remained random for the first half of the cumulative counts, but then became aggregated and remained so (Table 2). For fields $C$ and $D$, the spatial pattern was random during the first period (sample period 41), but then became aggregated in both of the fields after sample period 42 and remained so (Table 2).

Following aggregated major deposition events, subsequent contour maps of cumulative counts showed aggregates in the same areas of the field as the initial major event. This occurred in all three fields; an example is shown for field A (Fig. 4).

\section{DISCUSSION}

An integral phase of the FHB cycle on cereal crops is the deposition of airborne spores of G. zeae. The magnitude of spore deposition of G. zeae in a given field during a sampling interval has been shown to be affected by time of day (43-45), rainfall
(19), temperature, and humidity (32). Previous sampling efforts have not, however, addressed the spatial component of spore deposition of G. zeae. Here, we analyzed spatial patterns of spore deposition in 68 field environments during 54 individual day and night sample periods. Contour maps showed that the spatial pattern of spore deposition in each field environment was unique. SADIE analysis and Mantel tests demonstrated that nearly all of the spatial patterns of spore deposition in each field environment were random. These observations are consistent with previous reports of a predominantly random spatial pattern of FHB in rotational wheat fields (11). Aggregated patterns of FHB were observed in only a few wheat fields, all of which contained overwintered corn debris (11). Observed spatial patterns of FHB might result from similar spatial patterns of viable spore deposition, though this was not tested in our study.

Nearly half of the field environments with random patterns of spore deposition were observed during the day. The unstable

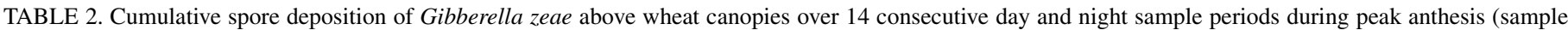

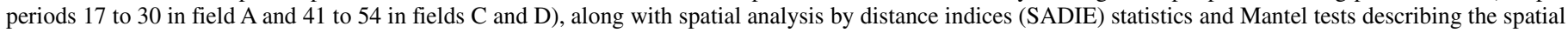
patterns of cumulative counts for each increment

\begin{tabular}{|c|c|c|c|c|c|c|c|c|}
\hline \multirow[b]{2}{*}{ Period } & \multirow[b]{2}{*}{ Field } & \multirow[b]{2}{*}{ Cumulative mean ${ }^{\mathrm{a}}$} & \multicolumn{3}{|c|}{ SADIE statistics } & \multicolumn{3}{|c|}{ Mantel statistics } \\
\hline & & & $I_{a}^{\mathrm{b}}$ & $P_{a}^{\mathrm{c}}$ & Pattern $^{\mathrm{d}}$ & $r^{\mathrm{e}}$ & $P^{\mathrm{f}}$ & Patterng \\
\hline 17 & A & 0.2 & 1.026 & 0.365 & Random & 0.033 & 0.710 & Random \\
\hline 18 & A & 37.4 & 0.968 & 0.487 & Random & -0.076 & 0.382 & Random \\
\hline 19 & A & 37.4 & 0.971 & 0.477 & Random & -0.074 & 0.395 & Random \\
\hline 20 & A & 601.1 & 1.069 & 0.282 & Random & 0.161 & 0.060 & Random \\
\hline 21 & A & 615.8 & 1.075 & 0.274 & Random & 0.160 & 0.067 & Random \\
\hline 22 & A & 778.7 & 1.177 & 0.154 & Random & 0.213 & 0.017 & Random \\
\hline 23 & A & 778.7 & 1.181 & 0.148 & Random & 0.213 & 0.015 & Random \\
\hline 24 & A & 884.6 & 1.579 & 0.009 & Aggregated & 0.274 & 0.004 & Aggregated \\
\hline 25 & A & 885.0 & 1.582 & 0.008 & Aggregated & 0.274 & 0.005 & Aggregated \\
\hline 26 & $\mathrm{~A}$ & 893.7 & 1.581 & 0.009 & Aggregated & 0.279 & 0.002 & Aggregated \\
\hline 27 & A & 893.9 & 1.583 & 0.010 & Aggregated & 0.278 & 0.002 & Aggregated \\
\hline 28 & A & 929.8 & 1.661 & 0.006 & Aggregated & 0.298 & 0.002 & Aggregated \\
\hline 29 & A & 930.3 & 1.663 & 0.004 & Aggregated & 0.298 & 0.001 & Aggregated \\
\hline 30 & A & 936.0 & 1.682 & 0.005 & Aggregated & 0.304 & 0.002 & Aggregated \\
\hline 41 & $\mathrm{C}$ & 23.9 & 1.322 & 0.050 & Random & 1.322 & 0.050 & Random \\
\hline 42 & $\mathrm{C}$ & 108.9 & 1.632 & $<0.001$ & Aggregated & 1.632 & $<0.001$ & Aggregated \\
\hline 43 & $\mathrm{C}$ & 110.9 & 1.687 & $<0.001$ & Aggregated & 1.687 & $<0.001$ & Aggregated \\
\hline 44 & $\mathrm{C}$ & 125.6 & 1.649 & $<0.001$ & Aggregated & 1.649 & $<0.001$ & Aggregated \\
\hline 45 & $\mathrm{C}$ & 126.5 & 1.678 & $<0.001$ & Aggregated & 1.678 & $<0.001$ & Aggregated \\
\hline 46 & $\mathrm{C}$ & 133.8 & 1.625 & $<0.001$ & Aggregated & 1.625 & $<0.001$ & Aggregated \\
\hline 47 & $\mathrm{C}$ & 134.4 & 1.651 & $<0.001$ & Aggregated & 1.651 & $<0.001$ & Aggregated \\
\hline 48 & $\mathrm{C}$ & 136.8 & 1.654 & $<0.001$ & Aggregated & 1.654 & $<0.001$ & Aggregated \\
\hline 49 & $\mathrm{C}$ & 137.2 & 1.646 & $<0.001$ & Aggregated & 1.646 & $<0.001$ & Aggregated \\
\hline 50 & $\mathrm{C}$ & 141.0 & 1.652 & 0.001 & Aggregated & 1.652 & 0.001 & Aggregated \\
\hline 51 & $\mathrm{C}$ & 141.7 & 1.651 & $<0.001$ & Aggregated & 1.651 & $<0.001$ & Aggregated \\
\hline 52 & $\mathrm{C}$ & 144.7 & 1.621 & 0.001 & Aggregated & 1.621 & 0.001 & Aggregated \\
\hline 53 & $\mathrm{C}$ & 144.7 & 1.621 & 0.001 & Aggregated & 1.621 & 0.001 & Aggregated \\
\hline 54 & $\mathrm{C}$ & 145.6 & 1.662 & 0.001 & Aggregated & 1.662 & 0.001 & Aggregated \\
\hline 41 & $\mathrm{D}$ & 22.0 & 1.075 & 0.279 & Random & 1.075 & 0.279 & Random \\
\hline 42 & $\mathrm{D}$ & 189.8 & 1.755 & $<0.001$ & Aggregated & 1.755 & $<0.001$ & Aggregated \\
\hline 43 & $\mathrm{D}$ & 192.4 & 1.768 & $<0.001$ & Aggregated & 1.768 & $<0.001$ & Aggregated \\
\hline 44 & $\mathrm{D}$ & 220.8 & 1.785 & $<0.001$ & Aggregated & 1.785 & $<0.001$ & Aggregated \\
\hline 45 & $\mathrm{D}$ & 221.5 & 1.789 & $<0.001$ & Aggregated & 1.789 & $<0.001$ & Aggregated \\
\hline 46 & $\mathrm{D}$ & 227.8 & 1.785 & $<0.001$ & Aggregated & 1.785 & $<0.001$ & Aggregated \\
\hline 47 & $\mathrm{D}$ & 227.9 & 1.785 & $<0.001$ & Aggregated & 1.785 & $<0.001$ & Aggregated \\
\hline 48 & $\mathrm{D}$ & 231.6 & 1.785 & $<0.001$ & Aggregated & 1.785 & $<0.001$ & Aggregated \\
\hline 49 & $\mathrm{D}$ & 232.1 & 1.786 & $<0.001$ & Aggregated & 1.786 & $<0.001$ & Aggregated \\
\hline 50 & $\mathrm{D}$ & 239.7 & 1.776 & $<0.001$ & Aggregated & 1.776 & $<0.001$ & Aggregated \\
\hline 51 & $\mathrm{D}$ & 240.2 & 1.777 & $<0.001$ & Aggregated & 1.777 & $<0.001$ & Aggregated \\
\hline 52 & $\mathrm{D}$ & 244.4 & 1.760 & $<0.001$ & Aggregated & 1.760 & $<0.001$ & Aggregated \\
\hline 53 & $\mathrm{D}$ & 244.4 & 1.761 & $<0.001$ & Aggregated & 1.761 & $<0.001$ & Aggregated \\
\hline 54 & $\mathrm{D}$ & 247.4 & 1.762 & $<0.001$ & Aggregated & 1.762 & $<0.001$ & Aggregated \\
\hline
\end{tabular}

a Mean cumulative count of spore deposition (average cumulative number of spores of $G$. zeae collected at a sample location) over consecutive sample periods.

b SADIE index of aggregation $\left(I_{a}\right)$ (37). Uniform, random, and aggregated spatial patterns of counts are suggested by $I_{a}$ of $<1$, =1, or $>1$, respectively.

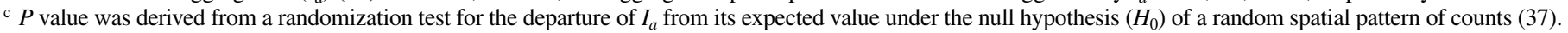

d Descriptions of random or aggregated spatial patterns of counts. $H_{0}$ was rejected if $P_{a}<0.01$, favoring the alternative hypothesis of aggregation.

e Normalized Mantel statistic $(r)$.

f $P$ value was derived from a randomization test for the departure of $r$ from its expected value under $H_{0}$ of a random spatial pattern of counts.

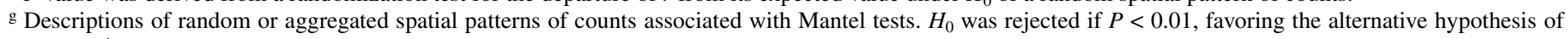
aggregation. 
atmosphere during the day may favor a random pattern of spores within the canopy. Aylor (2) observed that pollen can move relatively great distances in air currents within plant canopies during the day before being impacted on plant surfaces or settling out of the atmosphere by gravity. Other bioaerosols, such as spores of G. zeae, are likely to travel in a similar way. The random patterns of spore deposition are indicative of well-mixed sources of aerial inoculum (11).

Conversely, all of the field environments with aggregated patterns of spore deposition were observed at night. The stable atmosphere during the night may favor the settling of uneven clouds of spores of G. zeae out of the air. Ferrandino and Aylor (17) observed that urediniospores of Uromyces phaseoli traveled through the air predominantly in clusters. Although spore clusters may not necessarily result in aggregated patterns of spores over a field, the idea that spores may travel at higher densities in clumps or pockets of air should be considered. Aggregation of spores
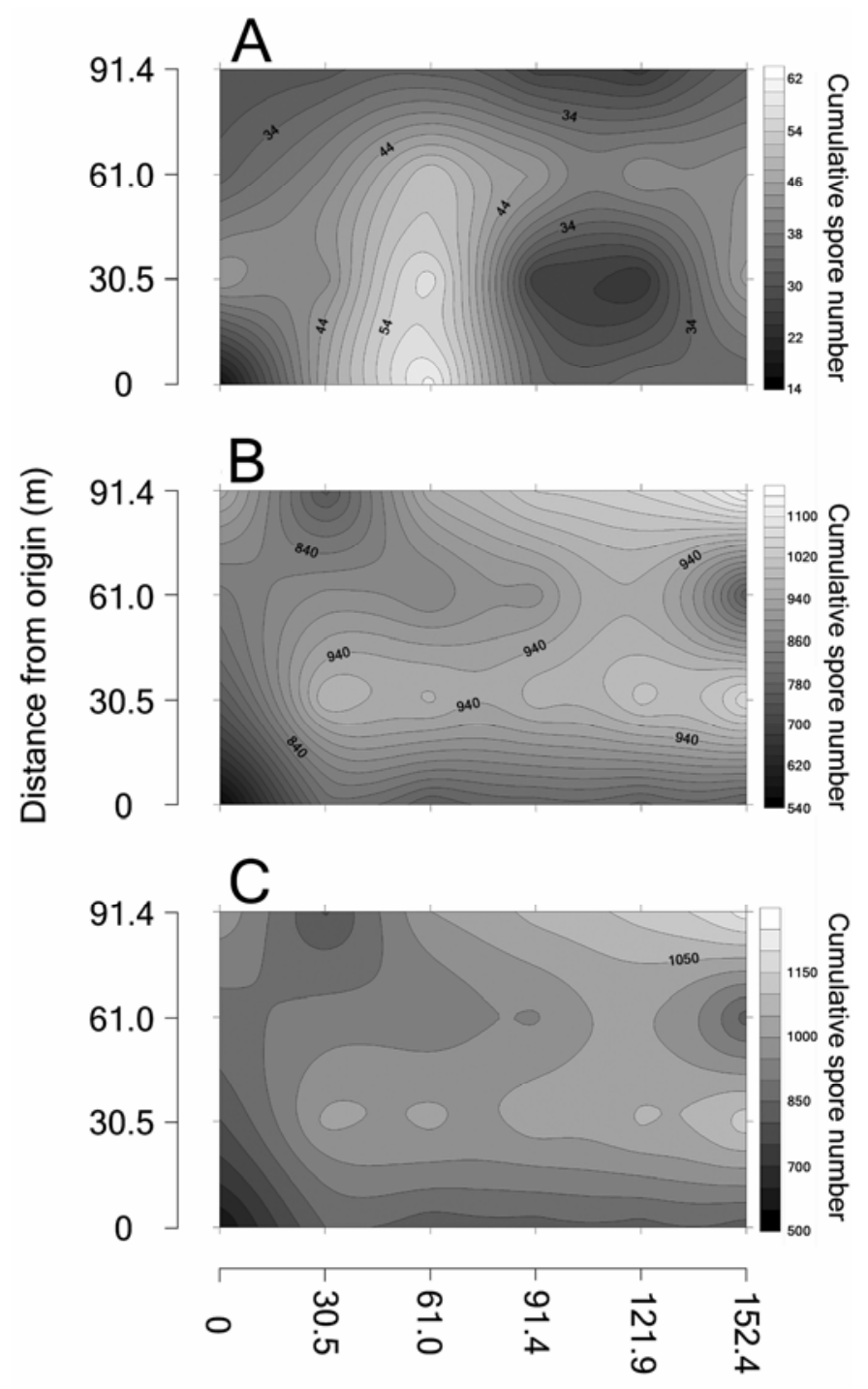

\section{Distance from origin $(\mathrm{m})$}

Fig. 4. Contour maps depicting the spatial patterns of cumulative spore deposition of Gibberella zeae during anthesis in field A for sample periods A, 19 (random pattern), B, 24 (aggregated pattern), and C, 30 (aggregated pattern). Contours were constructed based on cumulative counts of spores during anthesis at 24 equidistant sample locations within the field. Total spore counts (from both plates combined) at each sample location were matched with their associated $\left(X_{i}, Y_{i}\right)$ positions, and contour maps were constructed from these coordinates. Legends for the cumulative amount of spores deposited are presented to the immediate right of the contour maps. would provide greater numbers of propagules at particular locations in a field, resulting in increased inoculum pressure on plants at that location.

Only random patterns of spore deposition were observed during sample periods with rainfall. The deposition of airborne spores may be hastened by spores being washed out of the air during rainfall $(3,31)$, but the attribution of spatial patterns of spore deposition to rainfall is unclear.

Spores deposited over the experimental fields in this study were likely from a well-mixed aerial source of inoculum, potentially a combination of both local and more distant sources of G. zeae. None of the experimental fields contained cereal debris (a known inoculum source of $G$. zeae), nor were they within close proximity to concentrated sources of inoculum which would give rise to previously observed gradients $(12,15)$. Surrounding fields with cereal debris would represent large area sources from which pronounced deposition gradients are unlikely $(16,48)$. Furthermore, viable spores of $G$. zeae have been sampled at sites kilometers from known inoculum sources (20), suggesting that spores of the pathogen can be transported over great distances in the atmosphere.

Observed patterns of spore deposition during individual sample periods were independent of the mean number of viable spores deposited. However, cumulative spore deposition during anthesis in both years appeared to become aggregated over time. In part, this may be due to a disproportionate influence of one or more large-magnitude deposition events. Following aggregated major deposition events, subsequent contour maps of cumulative counts showed aggregates in the same areas of the field as the initial major event. The direct measure of exposure of wheat spikes to viable airborne spores may help to refine estimates of relative risk for FHB. Contour maps of daily and cumulative spore deposition could be compared with contour maps of FHB incidence to gain insights into the timing of effective inoculum for infection and of inoculum thresholds.

Risk assessment models have been developed for predicting epidemics of FHB (13) and resulting mycotoxin contamination in wheat (22); however, precise inoculum thresholds have not been defined in risk models for FHB. In theory, a single viable spore of G. zeae may infect a single wheat spike and produce symptoms of FHB. However, Stack (47) showed that a 10-fold difference in spore catch is required to detect differences in disease in the field. Most of the spore deposition events in rotational wheat fields were random; therefore, the number of viable spores deposited on randomly placed plates may adequately predict spore deposition in entire fields, provided that adequate model inoculum thresholds can be developed.

\section{ACKNOWLEDGMENTS}

This research was supported in part by Cornell University Hatch Project NYC153433.

\section{LITERATURE CITED}

1. Andersen, A. L. 1948. The development of Gibberella zeae headblight of wheat. Phytopathology 38:595-611.

2. Aylor, D. 1975. Deposition of particles in a plant canopy. J. Appl. Meteorol. 14:52-57.

3. Aylor, D. 1998. The aerobiology of apple scab. Plant Dis. 82:838-849.

4. Bassanezi, R. B., Bergamin Filho, A., Amorim, L., Gimenes-Fernandes, N., Gottwald, T. R., and Bove, J. M. 2003. Spatial and temporal analyses of citrus sudden death as a tool to generate hypotheses concerning its etiology. Phytopathology 93:502-512.

5. Bowden, R. L., and Leslie, J. F. 1999. Sexual recombination in Gibberella zeae. Phytopathology 89:182-188.

6. Burgess, L. W., Summerell, B. A., Bullock, S., Gott, K. P., and Backhouse, D. 1994. Laboratory Manual for Fusarium Research. University of Sydney, New South Wales, Australia.

7. Campbell, C. L., and Madden, L. V. 1990. Introduction to Plant Disease Epidemiology. Wiley, New York. 
8. Charest, J., Dewdney, M., Paulitz, T., Philion, V., and Carisse, O. 2002. Spatial distribution of Venturia inaequalis airborne ascospores in orchards. Phytopathology 92:769-779.

9. Dale, M. R. T., Dixon, P., Fortin, M. J., Legendre, P., Myers, D. E., and Rosenberg, M. S. 2002. Conceptual and mathematical relationships among methods for spatial analysis. Ecography 25:558-577.

10. Dallot, S., Gottwald, T., Labonne, G., and Quiot, J. B. 2003. Spatial pattern analysis of Sharka disease (Plum pox virus strain M) in peach orchards of southern France. Phytopathology 93:1543-1552.

11. Del Ponte, E. M., Shah, D. A., and Bergstrom, G. C. 2003. Spatial patterns of Fusarium head blight in New York wheat fields suggest role of airborne inoculum. Online. Plant Health Progress DOI:10.1094/PHP2003-0418-01-RS.

12. De Luna, L., Bujold, I., Carisse, O., and Paulitz, T. C. 2002. Ascospore gradients of Gibberella zeae from overwintered inoculum in wheat fields. Can. J. Plant Pathol. 24:457-464.

13. De Wolf, E. D., Madden, L. V., and Lipps, P. E. 2003. Risk assessment models for wheat Fusarium head blight epidemics based on within-season weather data. Phytopathology 93:428-435.

14. Fernando, W. G. D., Miller, J. D., Seaman, W. L., Seifert, K., and Paulitz, T. A.. 2000. Daily and seasonal dynamics of airborne spores of Fusarium graminearum and other Fusarium species sampled over wheat plots. Can. J. Bot. 78:497-505.

15. Fernando, W. G. D., Paulitz, T. C., Seaman, W. L., Dutilleul, P., and Miller, J. D. 1997. Head blight gradients caused by Gibberella zeae from area sources of inoculum in wheat field plots. Phytopathology 87:414-421.

16. Ferrandino, F. J. 1996. Length scale of disease spread: Fact or artifact of experimental geometry. Phytopathology 86:806-811.

17. Ferrandino, F. J., and Aylor, D. E. 1987. Relative abundance and deposition gradients of urediniospores of Uromyces phaseoli. Phytopathology 77:107-111.

18. Fortin, M. J., and Gurevitch, J. 2001. Mantel tests: Spatial structure in field experiments. Pages 308-326 in: Design and Analysis of Ecological Experiments. 2nd ed. S. M. Scheiner and J. Gurevitch, eds. Oxford University Press, Oxford.

19. Francl, L. J., Markell, S., Ali, S., and Friesen, T. L. 2000. Gibberella zeae population dynamics: A progress report. Pages 144-146 in: Proc. 2000 Natl. Fusarium Head Blight Forum, Erlanger, KY.

20. Francl, L. J., Shaner, G., Bergstrom, G., Gilbert, J., Pedersen, W., DillMackey, R., Sweets, L., Corwin, B., Jin, Y., Gallenberg, D., and Wiersma, J. 1999. Daily inoculum levels of Gibberella zeae on wheat spikes. Plant Dis. 83:662-666

21. Gottwald, T. R., Reynolds, K. M., Campbell, C. L., and Timmer, L. W. 1992. Spatial and spatiotemporal autocorrelation analysis of citrus canker epidemics in citrus nurseries and groves in Argentina. Phytopathology 82:843-851.

22. Hooker, D. C., Schaafsma, A. W., and Tamburic-Ilincic, L. 2002. Using weather variables pre- and post-heading to predict deoxynivalenol content in winter wheat. Plant Dis. 86:611-619.

23. Legendre, P., and Fortin, M.-J. 1989. Spatial pattern and ecological analysis. Vegetatio 80:107-138.

24. Madden, L. V., and Hughes, G. 1995. Plant disease incidence: Distributions, heterogeneity, and temporal analysis. Annu. Rev. Phytopathol. 33:529-564.

25. Maldonado-Ramirez, S. L. 2001. Aerobiology of the wheat scab fungus, Gibberella zeae: Discharge, atmospheric dispersal, and deposition of ascospores. Ph.D. dissertation. Cornell University, Ithaca, NY.

26. Maldonado-Ramirez, S. L., Bergstrom, G. C., and Shields, E. J. 1999. Use of remote piloted vehicles in aerobiological studies of Gibberella zeae. Pages 93-95 in: Proc. 1999 Natl. Fusarium Head Blight Forum, Michigan State University, University Press, East Lansing, MI.

27. Mantel, N. 1967. The detection of disease clustering and a generalized regression approach. Cancer Res. 27:209-220.

28. Markell, S. G., and Francl, L. J. 2003. Fusarium head blight inoculum: Species prevalence and Gibberella zeae spore type. Plant Dis. 87:814-820.
29. Martin, R. A. 1988. Use of a high through-put jet sampler for monitoring viable airborne propagules of Fusarium in wheat. Can. J. Plant Pathol. 10:359-360.

30. McMullen, M. P., Jones, R., and Gallenberg, D. 1997. Scab of wheat and barley: A re-emerging disease of devastating impact. Plant Dis. 81:13401348.

31. Oke, T. R. 1987. Boundary Layer Climates. 2nd ed. Cambridge University Press, Cambridge.

32. Paulitz, T. C. 1996. Diurnal release of ascospores by Gibberella zeae in inoculated wheat plots. Plant Dis. 80:674-678.

33. Paulitz, T. C. 1999. Fusarium head blight: A re-emerging disease. Phytoprotection 80:127-133.

34. Perry, J. N. 1995. Spatial analysis by distances indices. J. Anim. Ecol. 64:303-314.

35. Perry, J. N. 1998. Measures of spatial pattern for counts. Ecology 79:1008-1017.

36. Perry, J. N., Liebhold, A. M., Rosenberg, M. S., Dungan, J., Miriti, M., Jakomulska, A., and Citron-Pousty, S. 2002. Illustrations and guidelines for selecting statistical methods for quantifying spatial pattern in ecological data. Ecography 25:578-600.

37. Perry, J. N., Winder, L., Holland, J. M., and Alston, R. D. 1999. Red-blue plots for detecting clusters in count data. Ecol. Lett. 2:106-113.

38. Pielou, E. C. 1977. Mathematical Ecology. John Wiley \& Sons, New York.

39. Pruvost, O., Gottwald, T. R., and Brocherieux, C. 1999. The effect of irrigation practices on the spatio-temporal increase of Asiatic citrus canker in simulated nursery plots in Reunion Island. Eur. J. Plant Pathol. 105:23-37

40. Salas, B., Steffenson B. J., Casper, H. H., Tacke, B., Prom, L. K., Fetch, T. G., and Schwarz, P. B. 1999. Fusarium species pathogenic to barley and their associated mycotoxins. Plant Dis. 83:667-674.

41. Schmale, D. G., III, and Bergstrom, G. C. 2003. Fusarium head blight. Online. The Plant Health Instructor. DOI:10.1094/PHI-I-2003-0612-01.

42. Schmale, D. G., III, and Bergstrom, G. C. 2004. Spore deposition of the ear rot pathogen, Gibberella zeae, inside corn canopies. Can. J. Plant Pathol. 26:591-595.

43. Schmale, D. G., III, Shah, D. A., and Bergstrom, G. C. 2004. Spatial patterns of viable spore deposition of Gibberella zeae in corn and wheat fields. (Abstr.) Phytopathology 94(suppl.):S93.

44. Schmale, D. G., III, Shields, E. J., and Bergstrom, G. C. 2002. Airborne populations of Gibberella zeae: Spatial and temporal dynamics of spore deposition in a localized Fusarium head blight epidemic. Page 178 in: Proc. 2002 Natl. Fusarium Head Blight Forum, Erlanger, KY.

45. Schmale, D. G., III, Shields, E. J., and Bergstrom, G. C. 2003. Night-time spore deposition of the Fusarium head blight pathogen, Gibberella zeae. (Abstr.) Phytopathology 93:S77.

46. Shaner, G. E. 2003. Epidemiology of Fusarium head blight of small grain cereals in North America. Pages 84-119 in: Fusarium Head Blight of Wheat and Barley. K. J. Leonard and W. Bushnell, eds. The American Phytopathological Society, St. Paul, MN.

47. Stack, R. W. 1989. A comparison of the inoculum potential of ascospores and conidia of Gibberella zeae. Can. J. Plant Pathol. 11:137-142.

48. Stack, R. W. 1997. Gradients of Fusarium head blight in wheat along transects away from a concentrated source of Gibberella zeae ascospore inoculum. Page 60 in: Current Research on Fusarium Head Blight of Small Grains. R. Stack, ed. North Dakota State University, Fargo.

49. Sutton, J. C. 1982. Epidemiology of wheat head blight and maize ear rot caused by Fusarium graminearum. Can. J. Plant Pathol. 4:195-209.

50. Turecheck, W. W., and Madden, L. V. 2000. Analysis of the association between the incidence of two spatially aggregated foliar diseases of strawberry. Phytopathology 90:157-170.

51. Upton, G. J., and Fingleton, B. 1985. Spatial Data Analysis by Example, Vol. 1: Point Pattern and Quantitative Data. John Wiley \& Sons, New York. 